\title{
ENTREVISTA
}

\section{"La estructura de trabajo que tenemos en la Utec es un factor clave. Somos muy disciplinados y proactivos. Tenemos fortalezas que otras universidades no tienen."}

\begin{abstract}
La Universidad Tecnológica de El Salvador participará en un evento internacional de primer nivel. Se trata de la coordinación de los programas de cooperación de educación superior Alfa III y Erasmus Mundus acción 2, organizado por la Comisión Europea, que tendrá lugar del 25 al 27 de junio en Lima, Perú. Blanca Ruth Orantes, Directora de Investigación y de Relaciones Internacionales de la Utec será la representante de El Salvador y Centroamérica. Su participación será en calidad de coordinadora y miembro fundador de la Red Inca.
\end{abstract}

¿En qué consiste su participación en el evento que se desarrollará en junio próximo en Perú?

La Comisión Europea, cada tres o cuatro años, realiza un evento internacional para evaluar los resultados de algunos de los proyectos que ha financiado en diferentes regiones del mundo. Hoy el evento al que hemos sido invitados se va a realizar en Latinoamérica, específicamente en Perú, y van a asistir coordinadores de los proyectos de Europa y de Latinoamérica.

¿Es la primera vez que la Utec participa en este tipo de eventos internacionales?

Sí. Lo que se busca es básicamente reunir a la comunidad académica de Latinoamérica y Europa para discutir temas relevantes bajo un enfoque global, es decir, no solo viendo a Latinoamérica aislada de Europa, sino esa integración para el fortalecimiento de la educación superior vinculada con lo que es el desarrollo tecnológico y académico y de capacidades a nivel país del talento humano; dentro de ellos, las universidades o las entidades de educación superior tienen un papel activo, precisamente porque también son beneficiarias y administradoras de los proyectos. La Utec está teniendo un papel protagónico dentro de la Red Inca, que es un proyecto que nace en el 2008 bajo la cooperación de Alfa III y que reúne a universidades públicas y privadas de Centroamérica. La Utec es miembro fundador de una red que se ha constituido fuertemente y que es vinculada a universidades de primer orden en Centroamérica. Somos recomendados y seleccionados por un socio europeo para participar. Entonces, yo voy a representar a la Utec y al proyecto Red Inca.
¿Su participación es como coordinadora?

Sí, como coordinadora y como miembro fundador de la Red. Este evento es una gran oportunidad no solo para la universidad, sino a escala país porque, además de analizar o discutir cómo han sido los resultados de Alfa III y de Eramus Mundus acción 2, se va a dar información sobre el nuevo programa de cooperación para el sector de la educación superior en los próximos cuatro años.

¿En qué consiste este nuevo programa de cooperación?

Sé que tiene un enfoque global; y como eje siempre es apoyar a la educación superior en las instituciones de Latinoamérica. En este evento se van a conocer las nuevas estrategias, las nuevas líneas de cooperación y los requisitos.

¿Cuáles son los programas a los que tiene acceso la Utec?

Son líneas de cooperación; y allí hay varios proyectos. Ellos le llaman programas. Por ejemplo, el programa de cooperación Alfa III; y el otro es Erasmus Mundus acción 2 , en el que hay socios de Latinoamérica y de Europa. Estos (los proyectos) son becas con movilidades en los ámbitos administrativo y académico desde pregrado hasta postdoctorado.

¿En qué momento la Utec decide buscar socios estratégicos y desarrollar este tipo de alianzas?

Realmente los esfuerzos de la universidad datan de muchos años atrás. Cuando nosotros revisamos algunos convenios 
y algunas colaboraciones que la universidad ha realizado no solo a escala nacional, sino también internacional, vemos que los esfuerzos tienen su origen hace veinte años. Sin embargo, a partir del 2007 comienza una nueva era en la que las relaciones internacionales comienzan a tener un auge en las universidades. Y cuando digo relaciones internacionales no me refiero solo a los programas de cooperación, sino también al reconocimiento de las embajadas en el país y de organismos internacionales, en donde ya somos invitados a participar no solo en proyectos, sino a conocer las actividades que ellos realizan. Un ejemplo de estas alianzas es la ayuda que obtuvo el doctor Ramón Rivas de parte de la agencia de cooperación JICA para desarrollar la sala de migraciones en el Museo Universitario de Antropología (MUA) o las relaciones que se han establecido con la Universidad de Granada, que dieron lugar a que se impartiera un doctorado; así como con la Universidad Castilla de La Mancha, con la que se han realizado proyectos de investigación en conjunto.

¿Qué factores han influido para que la Utec se ubique en una posición importante y sea tomada en cuenta en eventos de primer nivel?

La estructura de trabajo que tenemos en la universidad es un factor clave, porque, cuando ya nos conocen, ven que nosotros somos muy disciplinados, somos muy proactivos, es decir, que tenemos unas fortalezas que otras universidades no tienen. En la Red Inca, por ejemplo, la primera junta directiva nos otorgó el lugar para ocupar la secretaría; y era una universidad por país, un representante por país. Eso significa que entre la UES y nosotros nos seleccionaron; y fue por votación. Eso fue allá en noviembre de 2011, es decir, es un reconocimiento que hace ver que sí tenemos las capacidades. Pertenecer a redes también nos permite contar con socios para los proyectos que estamos desarrollando y para los proyectos que van surgiendo.

\section{¿Quiénes son los socios estratégicos de la Utec?}

Hemos tenido movilidades para Costa Rica, Honduras, Nicaragua que han sido financiados. Por otra parte, en Europa hemos tenido beneficio. Ya tenemos estudiantes en países europeos, en instituciones de mucho prestigio como la Universidad Politécnica de Polonia y la Universidad de Mondragón, entre otras.

\section{¿En qué consiste la internacionalización?}

La internacionalización se mueve por programas. Y estos programas lo que buscan es fortalecer, en primer lugar, las funciones de educación superior, pero también mejorar la calidad de los estudiantes. El hecho de hacer movilidades y estar en otro país le puede permitir mejorar las competencias. Entonces, la internacionalización tiene como finalidad proporcionar beneficios en el quehacer de las universidades. Ahora bien, lo que se vaya consiguiendo o lo que se vaya obteniendo es la forma en cómo se hacen las relaciones internacionales; y el arte está en saber identificar aquellos proyectos que le convienen a la institución de educación superior.

¿Considera usted que la Utec ha sido líder en este proceso de internacionalización?

Sin lugar a equivocarme, creo que tenemos liderazgo. Y esto lo demuestra la universidad porque la internacionalización tiene que ver con la docencia, con la investigación, en la proyección social y la parte administrativa, porque todo es un conjunto.

\section{¿Cuántos representantes de El Salvador asistirán a Lima, Perú?}

Solo voy yo. Y me atrevería a decir que de Centroamérica soy la única representante, porque Inca es centroamericana; el otro representante que asistirá es de la Universidad Tecnológica de Panamá, quien va por el proyecto Pila.

\section{Actualmente ¿cuántos proyectos internacionales tiene} la Utec?

Tenemos alrededor de 29. Hay unos que están por finiquitarse; $y$ cuando le digo proyectos me refiero a diversas colaboraciones en la parte de investigación, movilidades, de cooperación, financiación directa o indirecta; es decir, se obtiene una serie de beneficios; pero lo mejor es que también posicionan a la universidad a escala regional e internacional. También hay un efecto colateral, el cual es que, al ser reconocido, se llenan criterios de calidad nacional e internacional. Entonces eso va a permitir, en el tiempo, que nosotros a lo mejor obtengamos un sistema de calidad interno que nos acredite a escala internacional, porque nuestros docentes y estudiantes van a poder acreditarse 
en diferentes agencias al cumplir con los requisitos que se exigen en ese nivel.

¿Estos procesos permiten visibilizar a una institución de educación superior?

Sí. Y por eso dicen, aquí, que es un enfoque global. Esto de la internacionalización es más amplio: pasa por la disciplina, el compromiso y cumplir la palabra. Estos eventos de coordinación Alfa III y Erasmus Mundus acción 2 son una oportunidad donde se tendrá una ronda de negocios, exposiciones de los proyectos y la oportunidad de hacer nuevos contactos; y por el hecho que a usted lo conozcan, ya lo contactan para otros proyectos.

Al momento de participar en un proyecto, ¿cuál es la selección que se hace?

En los procesos internacionales uno debe estar alerta, pero también saber distinguir si los proyectos nos van o no. Por ejemplo, tuvimos una oportunidad de aplicar a un proyecto en la India. Me senté con el decano de la Facultad de Informática y Ciencias Aplicadas, el ingeniero Francisco Armando Zepeda, y le dije que no participáramos porque nosotros no teníamos las líneas que ellos establecían. En los procesos de internacionalización siempre hay que estar listos a identificar lo que necesitamos o lo que nos puede servir en las líneas estratégicas que tenemos en la universidad. Porque ese es otro factor importante: que no nos vamos a mover como va la ola, sino que debemos de conocer las líneas estratégicas a futuro y cómo pueden fortalecernos esos procesos.

¿Cuáles son los programas puntuales en los que ha participado la Utec?

Hemos participado en el programa Alfa III de la comisión europea. Tenemos proyectos con Erasmus Mundus acción 2, en el programa Global Training; con la RLCU, que es la Red Latinoamericana de Cooperación Universitaria; Urdimbre, que es una red de educación e investigación; Pairca II, del Concejo Superior de Universidades de Centroamérica (CSUCA) y Red Inca, entre otros. 